\title{
Management of severe asthma
} exacerbation: guidelines from the Société Française de Médecine d'Urgence, the Société de Réanimation de Langue Française and the French Group for Pediatric Intensive Care and Emergencies

Philippe Le Conte ${ }^{1,2}$, Nicolas Terzi ${ }^{3,4^{*}}$, Guillaume Mortamet ${ }^{5}$, Fekri Abroug ${ }^{6}$, Guillaume Carteaux ${ }^{7}$, Céline Charasse ${ }^{8}$, Anthony Chauvin ${ }^{9}$, Xavier Combes ${ }^{10}$, Stéphane Dauger ${ }^{11}$, Alexandre Demoule ${ }^{12}$, Thibaut Desmettre ${ }^{13}$, Stephan Ehrmann ${ }^{14}$, Bénédicte Gaillard-Le Roux ${ }^{15}$, Valérie Hamel ${ }^{16}$, Boris Jung ${ }^{17}$, Sabrina Kepka ${ }^{18}$, Erwan L'Her ${ }^{19}$, Mikaël Martinez ${ }^{20,21}$, Christophe Milési ${ }^{22}$, Élise Morawiec ${ }^{23}$, Mathieu Oberlin ${ }^{24}$, Patrick Plaisance ${ }^{25}$, Robin Pouyau ${ }^{26}$, Chantal Raherison ${ }^{27}$, Patrick Ray ${ }^{28}$, Mathieu Schmidt ${ }^{29}$, Arnaud W. Thille ${ }^{30}$, Jennifer Truchot ${ }^{9}$, Guillaume Valdenaire ${ }^{31}$, Julien Vaux ${ }^{32}$, Damien Viglino ${ }^{4,33}$, Guillaume Voiriot ${ }^{34}$, Bénédicte Vrignaud ${ }^{35}$, Sandrine Jean ${ }^{36}$, Eric Mariotte ${ }^{37}$ and Pierre-Géraud Claret ${ }^{38}$

\begin{abstract}
Background: The French Emergency Medicine Society, the French Intensive Care Society and the Pediatric Intensive Care and Emergency Medicine French-Speaking Group edited guidelines on severe asthma exacerbation (SAE) in adult and pediatric patients.

Results: The guidelines were related to 5 areas: diagnosis, pharmacological treatment, oxygen therapy and ventilation, patients triage, specific considerations regarding pregnant women. The literature analysis and formulation of the guidelines were conducted according to the Grade of Recommendation Assessment, Development and Evaluation methodology. An extensive literature research was conducted based on publications indexed in PubMed ${ }^{\mathrm{TM}}$ and Cochrane $^{\mathrm{TM}}$ databases. Of the 21 formalized guidelines, 4 had a high level of evidence (GRADE $1+/-$ ) and 7 a low level of evidence (GRADE 2+/-). The GRADE method was inapplicable to 10 guidelines, which resulted in expert opinions. A strong agreement was reached for all guidelines.
\end{abstract}

Conclusion: The conjunct work of 36 experts from 3 scientific societies resulted in 21 formalized recommendations to help improving the emergency and intensive care management of adult and pediatric patients with SAE.

Keywords: Asthma, Severe exacerbation, Guidelines, Emergency, Intensive Care, Pediatric

\footnotetext{
*Correspondence: nterzi@chu-grenoble.fr

${ }^{3}$ Service de Médecine Intensive Réanimation, CHU de Grenoble Alpes, 38000 Grenoble, France

Full list of author information is available at the end of the article
} 


\section{Introduction}

One of the most frequent chronic illnesses, asthma, affects 300 million people worldwide, 30 million of them in Europe [1]. The term "acute asthma attack" is commonly used by patients, but corresponds to no clinical entity and should no longer be used. Asthma exacerbation is defined as an imbalance in the asthmatic disorder and is provoked acutely or subacutely by an external agent or by poor compliance with treatment [1]. Severe asthma exacerbation results from particularly severe bronchospasm and leads to severe obstructive syndrome. However, there is no consensual clinical definition of severe exacerbation $[2,3]$. In these guidelines, we have chosen to define severe asthma exacerbation (SAE) as asthma exacerbation that is life-threatening or requires emergency management or both [4].

\section{Aims of the guidelines}

The most recent guidelines by the Société de réanimation de langue française (SRLF) for severe acute asthma in adults date from 2002. In view of therapeutic advances in noninvasive ventilation (NIV) and high-flow oxygen therapy, recent international guidelines $[1,5,6]$ and the need to optimize practices [7], it seemed necessary to summarize current data. In this context, the Sociéte française de médecine d'urgence (SFMU) and the SRLF propose these expert guidelines on the management of severe asthma exacerbation.

\section{Method}

These guidelines were drawn up by a group of experts convened by the SFMU and the SRLF. The group's agenda was defined beforehand. The organizing committee first defined the questions to be addressed with the coordinators and then designated the experts in charge of each question. The questions were formulated according to a Patient Intervention Comparison Outcome (PICO) format after a first meeting of the expert group. The literature was analyzed and the guidelines were formulated using Grade of Recommendation Assessment, Development and Evaluation (GRADE) methodology. A level of proof was defined for each bibliographic reference cited depending on the type of study and could be reassessed in light of the methodological quality of the study. An overall level of proof was determined for each endpoint, taking into account the level of proof of each bibliographic reference, the between-study consistency of the results, the direct or indirect nature of the results, and cost analysis.

A high overall level of proof enabled formulation of a "strong" recommendation (should be done...GRADE 1+, should not be done...GRADE 1-). A moderate, low, or very low overall level of proof led to the drawing up of an "optional" recommendation (should probably be done... GRADE 2+, should probably not be done...GRADE 2-). When the literature was inexistent or insufficient, the question could be the subject of a recommendation in the form of an expert opinion (the experts recommend...). (Table 1) The proposed recommendations were presented and discussed one by one. The aim was not necessarily to reach a single and convergent opinion of the experts on all the proposals, but to define the points of agreement and the points of disagreement or uncertainty. Each expert then reviewed and rated each recommendation using a scale of 1 (complete disagreement) to 9 (complete agreement). The collective rating was done using a GRADE grid. To approve a recommendation regarding a criterion, at least $50 \%$ of the experts had to be in agreement and less than $20 \%$ in disagreement. For an agreement to be strong, at least $70 \%$ of the experts had to be in agreement. In the absence of strong agreement, the recommendations were reformulated and rated again, with a view to reaching a consensus. Only expert opinions that elicited strong agreement were kept.

\section{Areas of recommendations}

Five areas were defined: diagnosis and elements of the diagnosis, pharmacological treatment, methods of oxygen therapy and ventilation, transfer of patients, specific considerations regarding pregnant women. A bibliographic search was conducted using the MEDLINE database via PubMed and the Cochrane database. For inclusion in the analysis, the publications had to be written in English or French. The analysis focused on recent data according to

Table 1 Evidence grading and recommendations formulation

\begin{tabular}{ll}
\hline High level of evidence & Recommendations formulation according to GRADE \\
Intermediate to low level of evidence & Strong recommendation «should be...» \\
No or insufficient available data & Optional recommendation «should probably...» \\
Intermediate to low level of evidence & Expert opinion «the experts recommend...» \\
High level of evidence & Optional recommendation «should probably not...» \\
\hline
\end{tabular}


an order of appraisal ranging from meta-analyses to randomized trials to observational studies. A summary of the recommendations is presented in Table 2 .

\section{Results}

\section{First area: diagnosis and elements of the diagnosis}

For patients with asthma exacerbation, what severity criteria in medical history and at initial physical examination are associated with an increased risk of mortality and/or intensive care admission?

R1.1 adult-From first contact with patients with asthma exacerbation, the following severity criteria should be sought: history of hospital admission for asthma or need for mechanical ventilation, recent use of oral corticosteroids, considerable or increasing use of beta- 2 adrenergic agonists, age $>70$ years, difficulty speaking, altered consciousness, shock, respiratory rate $>30$ breaths $/ \mathrm{min}$, arguments in favor of an underlying pneumonia.

\section{GRADE $1+$, STRONG AGREEMENT}

\section{Rationale}

Several studies have tried to identify factors predictive of severe exacerbation in asthma patients. A 2005 metaanalysis [8] reported a significant association between the risk of death (fatal asthma) or the use of mechanical ventilation (near-fatal asthma) and the following factors: hospitalization for asthma exacerbation, in particular admission to intensive care in the previous 12-month period; history of exacerbation that prompted the use of mechanical ventilation; recent or ongoing treatment with oral corticosteroids; and considerable ( $\geq 1$ salbutamol inhaler per month) or increasing use of beta- 2 adrenergic agonists [9]. Lack of controller therapy with inhaled corticosteroids [8] and psychosocial factors $[10,11]$ seem to be associated with a higher risk of severe exacerbation. Published findings are conflicting. There are no data specific to risk evaluation by medical call centers. The abovementioned factors, along with difficulty speaking, are easily identifiable when a patient calls for emergency medical assistance. They are essential to assessment of asthma exacerbation severity and assessment of the risk of unfavorable progression. This should condition not only the medical decision at the call center, but also prehospital management and destination of patients transfer.

The criteria of clinical severity on admission of patients with SAE have mainly been investigated in observational studies [1]. The criteria of poor prognosis used in these studies were death or the need for mechanical ventilation. In patients admitted to intensive care, advanced age, neurological disorders, and tachycardia were clinical features associated with a poor prognosis [12, 13]. Data concerning hospitalized patients were reported by a 2017
Japanese publication [14]. Age (> 70 years), shock, altered consciousness, and infectious lung disease were associated with increased risk of death. Peak expiratory flow (PEF) measured at admission was seldomly studied, but was not associated with a poor prognosis $[15,16]$.

R1.1 pediatric-From first contact with children with asthma exacerbation, the following severity criteria should probably be sought: allergens polysensitization, insufficiently treated or poorly controlled asthma, history of hospitalization for asthma, exposure to passive smoking, and hypoxemia at initial management.

\section{GRADE $2+$, STRONG AGREEMENT}

\section{Rationale}

Only three prospective studies, all of them single-center, described the risk factors for death or admission to pediatric intensive care in case of severe asthma exacerbation in children [17-19]. The risk factors most commonly found are sensitization to multiple allergens, notably food allergens [17], history of hospitalization, especially admission to intensive care, or insufficiently controlled asthma (frequent nocturnal symptoms, frequent use of short-acting beta-2 adrenergic agonists, of oral corticosteroids, or of pediatric emergency services). Exposure to passive smoking and marked hypoxemia at initial management (oxygen saturation $<91 \%$ in ambient air) were reported as factors predictive of admission to intensive care in, respectively, three retrospective case-control studies and one retrospective case-control study.

\section{First area: diagnosis and elements of the diagnosis}

Should additional examinations be performed in patients with SAE in an emergency situation?

R1.2 adult-In SAE, chest radiography and blood gas measurements (venous or arterial) should probably be done if there is a diagnostic doubt or non-response to treatment.

\section{GRADE 2+, STRONG AGREEMENT}

\section{Rationale}

A cohort study failed to show any value of routine chest radiography in patients with SAE [20]. However, several guidelines underline its value in eliminating differential diagnoses. Chest radiography is recommended for patients presenting with wheezing/dyspnea and meeting at least one of the following criteria: history of chronic obstructive pulmonary disease, heart disease or thoracic surgery, suspicion of pneumonitis, immunosuppressed state. Arterial blood gas measurement should only be considered for SAE or exacerbations that fail to respond to initial treatment [21]. Normocapnia and hypercapnia are severity criteria of SAE. Measurement of venous blood 


\section{Table 2 Summary of recommendations}

R1.1 adult_-From first contact with patients with asthma exacerbation, the following severity criteria should be sought: history of hospital admission for asthma or need for mechanical ventilation, recent use of oral corticosteroids, considerable or increasing use of beta- 2 adrenergic agonists, age $>70$ years, difficulty speaking, altered consciousness, shock, respiratory rate $>30$ breaths/min, arguments in favor of an underlying pneumonia

R1.1 pediatric - From first contact with children with asthma exacerbation, the following severity criteria should probably be sought: allergens polysensitization, insufficiently treated or poorly controlled asthma, history of hospitalization for asthma, exposure to passive smoking, and hypoxemia at initial management

R1.2 adult — In SAE, chest radiography and blood gas measurements (venous or arterial) should probably be done if there is a diagnostic doubt or non-response to treatment

R1.2 pediatric-The experts suggest that additional examinations are not more effective at diagnosing SAE in children than physical examination alone

R2.1 - Beta-2 adrenergic agonists should not be administered intravenously first line in adult or pediatric patients with SAE even in mechanically ventilated patients

R2.2-Beta-2 adrenergic agonists should probably be administered by continuous rather than discontinuous nebulization during the first hour in adult and pediatric patients with SAE

R2.3- Inhaled anticholinergic drugs should be combined with beta-2 adrenergic agonists in adult and pediatric patients with SAE

R2.4-The experts suggest administering a 0.5 -mg dose of ipratropium bromide every $8 \mathrm{~h}$ in adults and children over 6 years of age, and a 0.25 -mg dose every $8 \mathrm{~h}$ in children under 6 years of age

R2.5 adult_-Systemic corticosteroid therapy should be administered early intravenously or orally ( $1 \mathrm{mg} / \mathrm{kg}$ of methylprednisolone equivalent, maximum $80 \mathrm{mg}$ per day) to all adult patients with SAE

R2.5 pediatric - Systemic corticosteroid therapy should probably be administered early intravenously or orally ( $2 \mathrm{mg} / \mathrm{kg}$ of methylprednisolone equivalent, maximum $80 \mathrm{mg}$ per day) to children with SAE

R2.6 adult-Magnesium sulfate should probably not be administered routinely to adult patients with SAE

R2.6 pediatric — Intravenous magnesium sulfate (dose $\geq 20 \mathrm{mg} / \mathrm{kg}$ ) should be administered routinely to pediatric patients with SAE

R2.7-Antibiotic therapy should probably not be administered routinely during SAE in adult and pediatric patients. Antibiotic therapy should probably be reserved for cases of suspected bacterial pneumonia, based on usual clinical, radiological, and laboratory signs

R3.1-Oxygen therapy titrated to a pulse oxygen saturation of $94 \%$ to $98 \%$ should probably be administered to adult and pediatric patients with SAE

R3.2 adult - The experts were unable to recommend the use of NIV in SAE. High-flow nasal oxygen therapy has yet to be assessed in this setting

R3.2 pediatric - The use of NIV in children with SAE should probably be considered when conventional treatments fail

R3.2 pediatric - The experts are unable to recommend the use of high-flow nasal oxygen in children with SAE

R3.3-The experts suggest resorting to intubation in adult and pediatric SAE patients if well-conducted medical treatment fails or if the inaugural clinical presentation is severe (altered consciousness, bradypnea). Intubation should be performed using the orotracheal route, after rapid sequence induction including ketamine in first line of hypnotic agent and succinylcholine or rocuronium, by an experienced physician

R3.4-The experts suggest prevention of lung overdistension by reducing tidal volume, respiratory rate, and positive end-expiratory pressure (PEEP), and by increasing inspiratory flow, in order to limit plateau pressure in mechanically ventilated adult and pediatric patients with SAE

R3.5 adult_-The experts suggest deep sedation-Richmond Agitation-Sedation Scale (RASS) of - 4 to - 5-at the initial phase of invasive mechanical ventilation, as well as neuromuscular blockers in the most severely ill patients. Their modalities are not specific to SAE. The experts are not able to recommend continuous administration of ketamine or halogenated agents

R3.5 pediatric-Ketamine and halogenated gas should probably not be used for the sedation of mechanically ventilated children with SAE

R3.6- Helium should probably not be used as carrier gas in nebulizers in adult and pediatric patients with SAE

R3.7 adult - The experts suggest that aerosols of salbutamol should be administered to spontaneously breathing patients with SAE using a nebulizer. The experts are unable to recommend a particular method of aerosol administration for patients with SAE receiving mechanical ventilation

R3.7 pediatric-The experts suggest providing a sufficient flow of air or oxygen to ensure the nebulization of inhaled treatments in spontaneously breathing children with SAE. The experts suggest continuing nebulization using specific systems in children with SAE who are mechanically ventilated

R3.8 - In the absence of compelling data in adult and pediatric patients with SAE, the experts suggest discussing with an expert center the use of extracorporeal life support—venovenous ECMO or extracorporeal CO2 removal (ECCO2R) —in the case of respiratory acidosis and/or severe hypoxemia refractory to optimal medical treatment and to well-conducted mechanical ventilation

R4.1 adult-The experts suggest that the decision to send patients with SAE home should be based on an assessment taking into account the patient's characteristics, the frequency of exacerbations, the severity of the initial clinical presentation, the response to treatment, including the progression of PEF, and the patient's ability to be managed at home (referral to the primary care physician)

R4.1 pediatric - The experts are unable to establish pediatric guidelines regarding the decision to send home children admitted for SAE

Grade 1+

Grade 2+

Grade 2+

Expert opinion

Grade 1-

Grade 2+

Grade 1+

Expert opinion

Grade 1+

Grade 2+

Grade 2-

Grade 1+

Grade 2-

Grade 2+

Expert opinion

Grade 2-

Expert opinion

Expert opinion

Expert opinion

Expert opinion

Grade 2-

Grade 2-

Expert opinion

Expert opinion

Expert opinion

Expert opinion

Expert opinion 
Table 2 (continued)

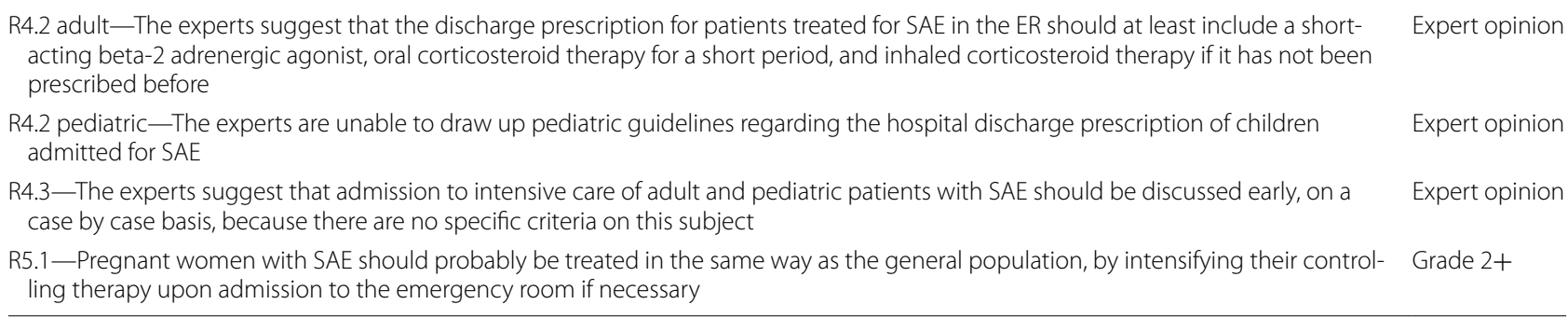

PCO2 is easier and less painful than arterial sampling, and a $\mathrm{PvCO} 2$ value below $45 \mathrm{mmHg}$ excludes arterial hypercapnia [22]. To date, lung ultrasound has not been evaluated in the diagnosis and management of asthma.

R1.2 pediatric-The experts suggest that additional examinations are not more effective at diagnosing SAE in children than physical examination alone.

\section{EXPERT OPINION}

\section{Rationale}

There is no pediatric study that has assessed the value of additional examinations in improving the reliability of the diagnosis of acute asthma in children. A single prospective, descriptive, single-center study has evaluated the value of chest ultrasound in acute asthma in children and reports that certain ultrasound signs may be associated with unfavorable progression [23]. Only chest radiography could be performed in case of clinical sign or medical history suggestive of an alternate diagnosis (no family history of asthma, fever, localized auscultatory abnormality).

\section{Second area: pharmacological treatment}

What are the methods of administration of beta- 2 adrenergic agonists in patients with SAE?

R2.1-Beta-2 adrenergic agonists should not be administered intravenously first line in adult or pediatric patients with SAE even in mechanically ventilated patients.

\section{GRADE 1-, STRONG AGREEMENT}

R2.2-Beta-2 adrenergic agonists should probably be administered by continuous rather than discontinuous nebulization during the first hour in adult and pediatric patients with SAE.

\section{GRADE $2+$, STRONG AGREEMENT}

\section{Rationale}

Numerous studies [20, 24, 25], including a Cochrane meta-analysis [26], have compared continuous and intermittent administrations of inhaled beta- 2 adrenergic agonists. Although there are few studies of high methodological quality, at identical doses, continuous administration was associated with a significant decrease in the number of hospitalizations, and with improvements in the ventilatory parameters forced expiratory volume in $1 \mathrm{~s}$ (FEV1) and PEF. The observed effect was greater in patients presenting with significant signs of respiratory airways obstruction [25]. This effect seems to be independent of the dose administered since a comparative study of 7.5 vs $2.5 \mathrm{mg} / \mathrm{h}$ in continuous nebulization resulted in a comparable improvement [24]. There was no increase in side effects or poor tolerance with continuous administration [26]. In adults, there is no proof of the advantage of using oxygen, compared with air, as the aerosol carrier gas in non-hypoxemic patients. The intravenous route offers no advantage over inhalation as it has been associated with more side effects [27].

There is no pediatric study that has rigorously compared the efficacy of continuous and intermittent nebulization of short-acting beta-2 adrenergic agonists in children with SAE. Several cohort studies have demonstrated that there is no increase in adverse effects (tachycardia, hypokalemia) with continuous versus intermittent nebulization $[28,29]$.

\section{Second area: pharmacological treatment}

Should anticholinergic drugs be added to inhaled beta- 2 adrenergic agonists in patients with SAE?

R2.3-Inhaled anticholinergic drugs should be combined with beta- 2 adrenergic agonists in adult and pediatric patients with SAE.

\section{GRADE $1+$, STRONG AGREEMENT}

R2.4-The experts suggest administering a 0.5-mg dose of ipratropium bromide every $8 \mathrm{~h}$ in adults and children over 6 years of age, and a 0.25 -mg dose every $8 \mathrm{~h}$ in children under 6 years of age.

EXPERT OPINIONS 


\section{Rationale}

The question of the addition of anticholinergic agents to bronchodilators has been addressed in several studies [30-32] and meta-analyses, including Cochrane studies in adults [33] and children [34]. Compared with the administration of beta- 2 adrenergic agonists alone, the anticholinergic/bronchodilator combination increased FEV1 and PEF. A significant decrease of about $30 \%$ in hospitalizations was observed. It nonetheless seemed that the benefit of anticholinergics was greater in patients with the lowest PEF on admission. Their use is, therefore, less recommended in patients with non-severe asthma exacerbation. The use of repeated doses of anticholinergic drugs during initial management of SAE patients has not been shown to be beneficial. There was an overall increase in adverse effects frequency (dry mouth, tremor, nausea, headache, agitation) with combination therapy compared with beta- 2 adrenergic agonists alone [32], without modification of the benefit-risk ratio. Despite a lack of data, the effect of anticholinergics in SAE seems to be unrelated to dose [35] and a single administration in the acute phase does not seem less effective clinically than a dose repeated every $60 \mathrm{~min}$ [33]. The experts propose a dosage regimen of $0.5 \mathrm{mg}$ of ipratropium bromide every $8 \mathrm{~h}$ for adults and children over 6 years of age and of $0.25 \mathrm{mg}$ every $8 \mathrm{~h}$ for children under 6 years of age.

\section{Second area: pharmacological treatment}

What are the methods of administration of corticosteroid therapy in patients with SAE?

R2.5 adult-Systemic corticosteroid therapy should be administered early intravenously or orally $(1 \mathrm{mg} / \mathrm{kg}$ of methylprednisolone equivalent, maximum $80 \mathrm{mg}$ per day) to all adult patients with SAE.

\section{GRADE $1+$, STRONG AGREEMENT}

\section{Rationale}

A meta-analysis has shown that it is important to administer corticosteroids early, during the first hour of management of patients with SAE [36]. There is no evidence that the intravenous route is superior to the oral route (unless the latter is contraindicated) [36]. Inhalation has not proven better than the intravenous and oral routes and does not seem to be necessary as an adjunct to these two routes [37]. High doses of corticosteroids have not proven superior to low doses. A dose not exceeding $80 \mathrm{mg} /$ day of methylprednisolone or $400 \mathrm{mg}$ of hydrocortisone, therefore, seems sufficient [38].

R2.5 pediatric-Systemic corticosteroid therapy should probably be administered early intravenously or orally (2 $\mathrm{mg} / \mathrm{kg}$ of methylprednisolone equivalent, maximum $80 \mathrm{mg}$ per day) to children with SAE.

\section{Rationale}

A single randomized, controlled, double-blind pediatric study [39] comparing the use of systemic corticosteroid therapy with inhaled corticosteroid therapy in SAE showed that systemic corticosteroid therapy was more effective in terms of respiratory parameters improvement. Other prospective studies [40-42] have yielded more heterogeneous results, given that they were conducted in smaller study populations or did not specify the severity of asthma exacerbations [43].

\section{Second area: pharmacological treatment}

Is magnesium sulfate indicated in patients with SAE?

R2.6 adult-Magnesium sulfate should probably not be administered routinely to adult patients with SAE.

GRADE 2-, STRONG AGREEMENT

\section{Rationale}

Intravenous or inhaled magnesium sulfate has been proposed as an adjuvant treatment of SAE because of its interesting experimental properties. However, there is no formal proof of its clinical efficiency. Several studies of low to modest level of proof have yielded discordant results. A well-conducted randomized, controlled study (3-Mg study) [44] showed no difference between asthma patients treated with magnesium sulfate or not regarding the need for hospital admissions, admissions to intensive care, the length of hospitalization, mortality, or the progression of dyspnea or PEF. Benign side effects were significantly more frequent in the magnesium group. It should nonetheless be pointed out that some studies suggest that magnesium sulfate is more effective in the most severely ill patients $[15,45-48]$, and that there is a certain heterogeneity in the studies regarding the disease severity of included patients. For example, the presence of clinical signs suggestive of a potentially life-threatening condition was an exclusion criterion for the $3 \mathrm{Mg}$ study and resulted in the exclusion of nearly $20 \%$ of the eligible patients. A meta-analysis [49] suggested a significant reduction in admissions to intensive care in patients treated with magnesium sulfate, but the heterogeneity of the studies limited the significance of this conclusion. In contrast, the studies were in agreement that this treatment had a relatively good safety profile and was not associated with severe side effects.

R2.6 pediatric-Intravenous magnesium sulfate (dose $\geq 20 \mathrm{mg} / \mathrm{kg}$ ) should be administered routinely to pediatric patients with SAE.

GRADE $1+$, STRONG AGREEMENT 


\section{Rationale}

A meta-analysis of five pediatric studies demonstrated, that in children with moderate to severe asthma exacerbation, magnesium sulfate improved respiratory parameters and reduced both the rate of hospitalization and the use of mechanical ventilation [50], which confirmed the findings of a previous randomized trial [51]. Studies have used different doses and methods of administration, but it seems that a dose equal to or greater than $20 \mathrm{mg} /$ $\mathrm{kg}$ is required. In contrast, nebulized magnesium sulfate seems to have no place in the treatment of asthma exacerbation in children [52].

\section{Second area: pharmacological treatment}

Should antibiotic therapy be administered to patients with SAE?

R2.7-Antibiotic therapy should probably not be administered routinely during SAE in adult and pediatric patients. Antibiotic therapy should probably be reserved for cases of suspected bacterial pneumonia, based on usual clinical, radiological, and laboratory signs.

\section{GRADE 2-, STRONG AGREEMENT}

\section{Rationale}

Respiratory infections are a frequent causal factor of SAE. Viruses play a major part, but bacterial infections may also be involved. Whereas the indication for antibiotic therapy is clear in the case of radiological opacity of the lung presumed to be of recent onset, its routine administration in SAE patients is debatable. In conclusion, several arguments may not encourage the routine administration of penicillin or of macrolides to adults with SAE requiring hospitalization [53-56]. Several teams have studied the value of routine antibiotic treatment in SAE requiring hospitalization. In adults, two randomized, controlled trials versus placebo assessed the benefits of routine administration of an oral macrolide for 3-10 days. The endpoint was the regression of respiratory symptoms at day 10 . The first trial, which was positive, had several limitations regarding the antibiotic used (telithromycin) and a high rate (61\%) of infection by intracellular bacteria in the population of the study [57]. The second trial, using azithromycin, was negative [58]. An older placebo-controlled trial showed no symptomatic benefit of antibiotic therapy with amoxicillin in an adult population [59]. A meta-analysis including trials in children and adults was also negative [60]. In conclusion, there is no argument encouraging the routine administration of penicillin or of macrolides to adults with SAE requiring hospitalization. No study focused specifically on the most severely ill population, i.e., patients with SAE requiring admission to intensive care.
Third area: methods of oxygen therapy and ventilation What are the methods of oxygen administration to patients with SAE?

R3.1-Oxygen therapy titrated to a pulse oxygen saturation of $94 \%-98 \%$ should probably be administered to adult and pediatric patients with SAE.

GRADE 2+, STRONG AGREEMENT

\section{Rationale}

Although patients with SAE are often hypoxemic [61], few studies have evaluated the way of administration of oxygen therapy in these patients: fixed-flow oxygen using a facial mask or administration titrated to pulse oxygen saturation between 94 and 98\%. The literature search revealed three studies with a low level of scientific proof (two randomized studies and one observational study) [62-64] that shared numerous biases: difficulties in conducting a blinded study, small study populations, short-term evaluation (20-60 min) and, especially, no evaluation of "hard" outcomes (rates of intubation, intensive care admission, hospitalization, death). A single study observed a deleterious effect of fixed-flow highconcentration oxygen therapy on PEF [63]. In contrast, three studies were in agreement regarding the effect of fixed-flow high-concentration oxygen therapy on the increase in $\mathrm{PaCO}_{2}$, compared with titrated oxygen therapy. This outcome alone does not allow a high level of recommendation in the absence of measured clinical impact, in contrast to data on other obstructive lung diseases like chronic obstructive pulmonary disease.

\section{Third area: methods of oxygen therapy and ventilation} Is there a role for non-invasive ventilation (NIV) or highflow oxygen therapy in patients with hypoxemic SAE?

R3.2 adult-The experts were unable to recommend the use of NIV in SAE. High-flow nasal oxygen therapy has yet to be assessed in this setting.

EXPERT OPINION

\section{Rationale}

NIV is increasingly used for the management of SAE $[65,66]$. In several observational studies, NIV improved alveolar ventilation and successes were even reported in patients with disturbance of consciousness and with severe hypercapnia. A single study has shown a reduction in the rate of intubation with NIV [67]. However, the conclusions of this retrospective, single-center, before-after study cannot be generalized. In a large American database, the rate of intubation of patients treated by NIV was identical to that of the other patients [68]. Four randomized 
controlled studies compared NIV with treatment without NIV [69-72]. All these studies reported clinical or spirometric (decrease in respiratory rate, dyspnea, and signs of struggling to breathe, improvement in FEV1 or PEF) improvement. These effects were sometimes accompanied by a reduction in the doses of salbutamol [70] and even in the risk of hospitalization and hospital stay. However, all these studies were in small numbers of patients (30-50). The authors of a systematic Cochrane review concluded that the data were insufficient to assess the effect of NIV on outcomes such as mortality, intubation, improvement in blood gases, and length of hospitalization [73]. In 2017, European and American societies were unable to formulate a recommendation because of the uncertainty and insufficiency of the data [74]. Although NIV seems to have beneficial clinical and spirometric effects, the experts are unable to recommend its use in SAE. No data are yet available regarding high-flow oxygen therapy.

R3.2 pediatric-The use of NIV in children with SAE should probably be considered when conventional treatments fail.

\section{GRADE 2+, STRONG AGREEMENT}

R3.2 pediatric-The experts are unable to recommend the use of high-flow nasal oxygen in children with SAE.

\section{EXPERT OPINION}

\section{Rationale}

Three prospective studies, two of which were randomized and controlled $[75,76]$, found an improvement in clinical parameters and blood gas results when using NIV in SAE [77]. On the other hand, none of these studies showed any benefit in terms of length of hospital stay or the need for invasive ventilation. Data on the use of nasal humidified high-flow oxygen come solely from retrospective studies $[78,79]$, and so it is currently impossible to recommend its use in clinical practice in children with SAE.

\section{Third area: methods of oxygen therapy and ventilation}

What are the indications for and methods of intubation in patients with SAE?

R3.3-The experts suggest resorting to intubation in adult and pediatric SAE patients if well-conducted medical treatment fails or if the inaugural clinical presentation is severe (altered consciousness, bradypnea). Intubation should be performed using the orotracheal route, after rapid sequence induction including ketamine in first line hypnotic agent and succinylcholine or rocuronium, by an experienced physician.

\section{Rationale}

Only $2 \%$ of patients hospitalized for SAE require intubation [80]. The usual clinical criteria are the only decision-making arguments for intubation. Given associated high morbidity and mortality rates, intubation will only be considered as a last resort, in case of failure of wellconducted medical treatment or when the clinical presentation is severe at the onset of management (altered consciousness, bradypnea) [81]. It should be performed in accordance with the latest expert guidelines [82] and should be preceded by adequate pre-oxygenation and rapid sequence induction. It should be performed by the most experienced operator so as to reduce the risks of complications [83]. The orotracheal route is preferred. NIV cannot be established as the favored method of pre-oxygenation, but seems logical given the results obtained in other populations of patients. The use of ketamine or propofol as the main hypnotic agent during rapid sequence induction can seem useful because of their theoretical bronchodilator effects [81]. However, no satisfactory scientific data formally validate their use in this indication. As in other indications for emergency intubation, it is justified to use a fast-acting neuromuscular blocker during anesthesia induction [82]. The scientific data concerning the intubation of patients with SAE are extremely limited and come principally from general reviews and expert opinions, or from retrospective cohort studies that are generally single-center and include small numbers of patients. No randomized study, for example, is available regarding methods of intubation. We can, therefore, only formulate an expert opinion.

There is no pediatric study on the indications for intubation in SAE, or on methods of intubation, and practices vary greatly [84]. The indications for intubation should be based on clinical judgment and it is probable that marked hypercapnia or hypoxia, or alterations of consciousness are indications for invasive mechanical ventilation requirement. In addition, a cuffed tracheal tube of the largest possible diameter should probably be preferred.

\section{Third area: methods of oxygen therapy and ventilation}

What are the methods of invasive ventilation in intubated patients with SAE?

R3.4-The experts suggest prevention of lung overdistension by reducing tidal volume, respiratory rate, and positive end-expiratory pressure (PEEP), and by increasing inspiratory flow, to limit plateau pressure in mechanically ventilated adult and pediatric patients with SAE.

EXPERT OPINION 


\section{Rationale}

At the initial phase of management of SAE, lung overdistension by mechanical ventilation is deleterious as it is associated with a risk of barotrauma and induces arterial hypotension [85]. Minute ventilation [65] should be minimized by limiting tidal volume to $6-8 \mathrm{~mL} / \mathrm{kg}[86,87]$, o [86], and by increasing inspiratory flow to $60-80 \mathrm{~L} / \mathrm{min}$ [88]. These goals are attained more easily in controlled volume mode, with constant inspiratory flow [85]. PEEP should be kept $\leq 5 \mathrm{cmH}_{2} \mathrm{O}$ [89]. Maintenance of plateau pressure $<30 \mathrm{cmH}_{2} \mathrm{O}$ [13] is associated with a better prognosis. Monitoring of intrinsic PEEP has no benefits $[86,90]$. All these settings are generally accompanied by often severe hypercapnia, which should be tolerated (except in the cases of cerebral edema, cranial trauma, and intracerebral mass). It is, therefore, legitimate to prefer a heated humidifier to a heat and moisture exchanger. There are no literature data that allow recommendation of a given value of inspired oxygen fraction $\left(\mathrm{FiO}_{2}\right)$ or an oxygenation target.

No pediatric study has compared one ventilator mode to another for invasive mechanical ventilation in SAE.

\section{Third area: methods of oxygen therapy and ventilation}

What are the methods of sedation for mechanically ventilated patients with SAE? Do halogenated anesthetics have a part to play?

R3.5 adult-The experts suggest deep sedation-Richmond Agitation-Sedation Scale (RASS) of -4 to -5 - at the initial phase of invasive mechanical ventilation, as well as neuromuscular blockers in the most severely ill patients. Their modalities are not specific to SAE. The experts are not able to recommend continuous administration of ketamine or halogenated agents.

\section{EXPERT OPINION}

\section{Rationale}

Deep sedation (RASS between -4 and -5 ) is often necessary at the initial phase of invasive ventilation given the marked activation of central respiratory drive by the conjunction of the respiratory condition itself, the large reduction in tidal volume, and hypercapnia. For the same reasons, it may be necessary to include continuous or transient neuromuscular block, in the most severely ill patients. Studies in these patients have reported an association between prolonged neuromuscular blockers by atracurium or vecuronium and neuromyopathy acquired in intensive care $[91,92]$. This unwanted effect should be taken into account. Among available intravenous sedatives, propofol has more marked bronchodilator properties than benzodiazepines. Because of its own bronchodilator effect, continuously administered ketamine (1-2 $\mathrm{mg} / \mathrm{kg} / \mathrm{h}$ in the adult) in addition to conventional sedation has been evaluated. Studies [93, 94] have reported benefits, at the cost of adverse effects (tachycardia, hallucination/confusion, hypersalivation) that are sometimes severe (myocardial infarction) [95]. Because of their bronchodilator properties, the benefits of halogenated agents (isoflurane and more recently sevoflurane) have been reported, especially in children [96]. An excellent understanding of the pharmacological properties, therapeutic modalities, and side effects of these agents is a necessary prerequisite to their administration.

R3.5 pediatric-Ketamine and halogenated gas should probably not be used for the sedation of mechanically ventilated children with SAE.

GRADE 2-, STRONG AGREEMENT

\section{Rationale}

A Cochrane meta-analysis [97] suggests that the use of ketamine in children with SAE provides no benefit. There is no other pediatric study on the use of "conventional" sedative agents in children with SAE. The literature on halogenated agents is essentially composed of retrospective studies in small populations and cannot be used to recommend their use in everyday practice $[98,99]$.

\section{Third area: methods of oxygen therapy and ventilation}

Does helium have a role as carrier gas for inhaled therapies in patients with SAE?

R3.6-Helium should probably not be used as carrier gas in nebulizers in adult and pediatric patients with SAE.

GRADE 2-, STRONG AGREEMENT

\section{Rationale}

Helium is an inert monoatomic gas whose medical applications are linked to its physical properties and absence of side effects. Compared with an air-oxygen mixture, a helium-oxygen mixture has a lower density and higher viscosity, which improve the transition from turbulent to laminar flow, thus reducing the density-dependent component of bronchial resistance. In SAE, a helium-oxygen mixture optimizes bronchial deposition of bronchodilators. The literature contains 11 prospective randomized trials in adults [100-110] and a meta-analysis [111] comparing nebulization of beta- 2 adrenergic agonists (most often albuterol) by a carrier gas composed of a heliumoxygen mixture and a standard mixture of air-oxygen, in patients with SAE. No definitive conclusion can be drawn because these studies were very heterogeneous and included small populations. 
Third area: methods of oxygen therapy and ventilation What are the methods of nebulization of therapeutic agents for patients with SAE?

R3.7 adult-The experts suggest that aerosols of salbutamol should be administered to spontaneously breathing patients with SAE using a nebulizer. The experts are unable to recommend a particular method of aerosol administration for patients with SAE receiving mechanical ventilation.

\section{EXPERT OPINION}

\section{Rationale}

A meta-analysis showed equivalent efficacy for nebulizers and metered-dose inhalers coupled to valved holding chambers (spacers) [112]. However, in spontaneously breathing patients with SAE, the experts prefer the use of nebulizers, given their greater ease of use and because they do not require the cooperation of the patient [113]. The vast majority of studies have used air- or oxygendriven pneumatic nebulizers. Oxygen-driven jet nebulization is preferable in the hypoxemic patient, but the expected $\mathrm{FiO} 2$ values are low because of the absence of an oxygen reservoir coupled to aerosol masks [114]. With their lower residual volume, ultrasonic nebulizers and vibrating mesh nebulizers have the same efficacy as pneumatic nebulizers and metered dose inhalers used with valved holding chambers [115]. In the absence of clinical evaluation in the setting of asthma, nebulization in a humidified nasal high-flow circuit cannot, at present, be recommended. Placing nebulizers within a high-flow nasal cannula oxygen therapy circuit is associated with a low amount of drug delivered in preclinical studies, and therefore does not seem advisable in the current state of knowledge at the time of guideline writing [116].

The recommendations regarding positive pressure respiratory assistance and high-flow oxygen therapy are only based on expert opinions, in vitro studies, and clinical studies with a high risk of bias in very few subjects. There is no randomized study that has specifically compared different aerosol generators in patients with SAE receiving mechanical ventilation. Ultrasonic nebulizers and vibrating mesh nebulizers and metered-dose inhalers are effective in this context when they can be adapted to the ventilator. There is no reason to alter the ventilator settings because of the administration of aerosols. It is essential to place a filter between the ventilator and the expiratory branch of the respiratory circuit, and to change it regularly [117].

R3.7 pediatric-The experts suggest providing a sufficient flow of air or oxygen to ensure the nebulization of inhaled treatments in spontaneously breathing children with SAE. The experts suggest continuing nebulization using specific systems in children with SAE who are mechanically ventilated.

EXPERT OPINION

\section{Rationale}

There are no pediatric data on the methods of nebulization in severe acute asthma in children.

\section{Third area: methods of oxygen therapy and ventilation}

What is the role of extracorporeal membrane oxygenation (ECMO) in patients with SAE?

R3.8-In the absence of compelling data in adult and pediatric patients with SAE, the experts suggest discussing with an expert center the use of extracorporeal life support-venovenous ECMO or extracorporeal $\mathrm{CO}_{2}$ removal (ECCO2R) - in the case of respiratory acidosis and/or severe hypoxemia refractory to optimal medical treatment and to well-conducted mechanical ventilation.

\section{EXPERT OPINION}

\section{Rationale}

To date, the literature on the use of extracorporeal life support (ECMO or ECCO2R) in the management of SAE is extremely limited. The available data are from small retrospective cohorts [118-121]. Review of the International Extracorporeal Life Support Organization Registry shows that ECMO was used in the setting of SAE in 24 of the 1257 patients included in the registry. Hospital survival was $83 \%$, compared with $51 \%$ in patients receiving venovenous ECMO for another cause [121]. As hypercapnia is prominent in refractory SAE, ECCO2R can be considered as a more accessible and less invasive technique than ECMO [118].

The use of extracorporeal life support in children with SAE has been described solely in clinical cases or in retrospective studies in small cohorts [120]. The survival rate in this indication seems good. The criteria for the use of extracorporeal life support have not been described in the literature.

\section{Fourth area: transfer of patients}

What are the criteria allowing hospital discharge of patients with SAE?

R4.1 adult-The experts suggest that the decision to send patients with SAE home should be based on an assessment taking into account the patient's characteristics, the frequency of exacerbations, the severity of the initial clinical presentation, the response to treatment, including the progression of PEF, and the 
patient's ability to be managed at home (referral to the primary care physician).

\section{EXPERT OPINION}

\section{Rationale}

A return home can be envisaged when the symptoms improve after a few hours of treatment in the emergency room. After an hour of continuous treatment with short-acting beta- 2 adrenergic agonists, a return home can be envisaged for patients with improved symptoms, no further need for nebulized beta- 2 adrenergic agonists, PEF that is $60 \%-80 \%$ of the patient's theoretical maximum value, pulse oxygen saturation $>94 \%$ in ambient air, and a favorable home environment [1]. No study has validated factors predicting readmission of SAE patients.

R4.1 pediatric-The experts are unable to establish pediatric guidelines regarding the decision to send home children admitted for SAE.

\section{EXPERT OPINION}

\section{Rationale}

There are no pediatric data on the subject.

\section{Fourth area: transfer of patients}

For patients treated for SAE, what modalities of hospital discharge from the emergency room reduce the risk of a severe adverse event?

R4.2 adult-The experts suggest that the discharge prescription for patients treated for SAE in the ER should at least include a short-acting beta- 2 adrenergic agonist, oral corticosteroid therapy for a short period, and inhaled corticosteroid therapy if it has not been prescribed before.

\section{EXPERT OPINION}

\section{Rationale}

No study has specifically focused on the outcome of patients with SAE not hospitalized after an emergency room stay. On discharge, health professionals must inform the patient and ensure that he or she has a personalized plan of action [1]. A recent meta-analysis did not allow a conclusion to be drawn regarding the impact of these personalized action plans on mortality rate in adults [122]. In contrast, education of the patient reduced the rate of hospitalization in the weeks following the emergency room stay [123]. As for oral corticosteroid therapy, there are no consistent data on the length of treatment, the type of drug or the dose to be preferentially used [124]. A recent Cochrane metaanalysis found no evidence for the additional value of inhaled corticosteroids, alone or combined with oral corticosteroid therapy, upon discharge from the emergency room [37]. However, recent guidelines [1] recommend initiation of inhaled corticosteroids in patients whose chronic treatment does not include them and the increase of their dosage for 2-4 weeks in patients already receiving inhaled corticosteroids. The discharge treatment should also include an inhaled short-acting beta- 2 adrenergic agonist and a prescription for PEF device for home monitoring.

R4.2 pediatric-The experts are unable to draw up pediatric guidelines regarding the hospital discharge prescription of children admitted for SAE.

EXPERT OPINION

\section{Rationale}

There are no pediatric data on the subject.

\section{Fourth area: transfer of patients}

For patients with SAE, what criteria are used to indicate transfer from the emergency room to intensive care?

R4.3-The experts suggest that admission to intensive care of adult and pediatric patients with SAE should be discussed early, on a case-by-case basis, because there are no specific criteria on this subject.

EXPERT OPINION

\section{Rationale}

No randomized study or large-scale case-control study has conclusively confirmed the criteria justifying intensive care unit admission of patients with SAE. However, epidemiological studies have identified the following epidemiological features correlated with admission to intensive care [68, 125-127]: living in a disadvantaged area, psychiatric illness, substance abuse (heroin, cocaine), poor perception of dyspnea, history of admission to intensive care for SAE, history of intubation for SAE, repeated use of short-acting beta- 2 adrenergic agonists, regular use of systemic corticosteroids. The clinical features correlated with admission to intensive care were as follows: clinical signs of respiratory distress, $\mathrm{PEF}<200 \mathrm{~L} /$ min, improvement in PEF of $<10 \%$ after treatment, signs of acute cor pulmonale, poor hemodynamic tolerance, hypercapnia $\left(\mathrm{PaCO}_{2} \geq 45 \mathrm{mmHg}\right)$ with or without acidemia, metabolic or mixed acidosis, abnormal chest radiography (barotrauma or lung disease). There are no 
references concerning criteria for the hospitalization of children in continuous monitoring or intensive care pediatric units. Age $<8$ years, a history of admission to intensive care for asthma, altered consciousness, and initial severity documented by a clinical score can be used to consider admission to intensive care or to a continuous monitoring unit $[128,129]$.

\section{Fifth area: specificities of the pregnant woman}

For pregnant women with SAE, does specific management improve morbidity and mortality of mother and fetus compared with standard management?

R5.1-Pregnant women with SAE should probably be treated in the same way as the general population, by intensifying their controlling therapy upon admission to the emergency room if necessary.

\section{GRADE $2+$, STRONG AGREEMENT}

\section{Rationale}

There is no study on specific management of SAE in pregnant women. Pregnant women with asthma exacerbation have been shown to receive fewer standard of care therapies in the emergency room [130]. During pregnancy, SAE is frequent and associated with an increased risk of maternal (pre-eclampsia, pre- and post-partum hemorrhage, prelabor rupture of membranes, placental detachment, placenta previa) and fetal and neonatal (growth restriction, hypotrophy, prematurity) complications [131-133]. During SAE, the benefits of treatments are much greater than the very low risk of malformation.

\section{Acknowledgements \\ Guidelines reviewed and endorsed by the SFMU (08/06/2018) and SRLF (12/06/2018) boards.}

\section{Authors' contributions}

PLC, NT and GM proposed the elaboration of these guidelines and manuscript in agreement with the "Société Française de Médecine d'Urgence", the "Société de Réanimation de Langue Française" and the "Groupe Francophone de Réanimation et d'Urgences Pédiatriques"; Pierre-Géraud Claret, Eric Mariotte and Sandrine Jean wrote the methodology section and gave the final version with the final presentation. FA, GC, AC, PGC, XC, AD, TD, VH, SH, BJ, SK, EL, PLC, EM, MM, ÉM, MO, PR, PP, CR, MS, NT, AT, JT, GV, JV, DV, GV contributed to the elaboration of adult guidelines. CC, SD, BGLR, SJ, CM, GM, RP, BV contributed to the elaboration of pediatric guidelines. All authors read and approved the final manuscript.

\section{Funding}

This work was financially supported by the SFMU (Grant Number 1) and the SRLF (Grant Number 1).

\section{Availability of data and materials}

Not applicable.

\section{Ethics approval and consent to participate}

Not applicable.
Consent for publication

Not applicable.

\section{Competing interests}

Philippe Le Conte reports personal fees from Novartis, outside the submitted work; Nicolas Terzi reports personal fees from Boehringer Inghelheim, personal fees from Pfizer, outside the submitted work; Guillaume Carteaux reports congress registration expanses from Orkyn, personal fees from Air Liquide Medical System, outside the submitted work; Alexandre Demoule reports personal fees from Medtronic, grants, personal fees and non-financial support from Philips, personal fees from Baxter, personal fees from Hamilton, personal fees and non-financial support from Fisher \& Paykel, grants from French Ministry of Health, personal fees from Getinge, grants and personal fees from Respinor, grants and non-financial support from Lungpacer; Stéphan Ehrmann reports consultancies fees from Aerogen, Baxter healthcare, Bayer medical and La DiffusionTechnique Française, research support from Aerogen, Fisher \& Paykel and Hamilton, travel expenses reimbursement from Aerogen and Fisher \& Paykel; Bénédicte Gaillard-Le Roux reports non-financial support from BAXTER NUTRITION, non-financial support from FRESENIUS, outside the submitted work; Boris Jung reports travel expenses reimbursement from Sedana Medical; Erwan L'Her reports grants and personal fees from Smiths Medical, General Electrics, Sedana Medical and Oxynov Inc., all outside the submitted work; Mikaël Martinez reports personnal fees from Astra Zeneca and Actélion, outside the submitted work; Chantal Raherison eports personal fees from Mundipharma, grants and personal fees from Astra Zeneca, personal fees from ALK, grants and personal fees from Boehringer Ingelheim, grants from Chiesi, grants and personal fees from Glaxo Smith Kline, grants and personal fees from Novartis, personal fees from Zambon, outside the submitted work; Mathieu Schmidt reports personal fees from Drager, personal fees from Getinge, personal fees from Xenios, outside the submitted work; Arnaud Thille reports personal fees from Fisher\&Paykel, personal fees from Covidien, personal fees from Maquet-Getinge, personal fees from GE healthcare, outside the submitted work; Damien Viglino reports grants from Mundipharma, from Astra Zeneca, outside the submitted work; Guillaume Voiriot reports grants, personal fees and non-financial support from Biomérieux, grants from Janssen, grants from SOS Oxygène, outside the submitted work; Eric Mariotte reports personal fees from Sanofi, outside the submitted work; Guillaume Mortamet, Fekri Abroug, Céline Charasse, Anthony Chauvin, Xavier Combes, Stéphane Dauger, Thibaut Desmettre, Valérie Hamel, Sabrina Kepka, Christophe Milési, Élise Morawiec, Mathieu Oberlin, Patrick Plaisance, Robin Pouyau, Patrick Ray, Jennifer Truchot, Guillaume Valdenaire, Julien Vaux, Bénédicte Vrignaud, Sandrine Jean, Pierre-Géraud Claret has nothing to disclose.

\section{Author details}

1 Service d'Accueil des Urgences, CHU de Nantes, 5 allée de lîle gloriette, 44093 Nantes Cedex 1, France. ${ }^{2}$ PHU3, Faculté de Médecine 1, rue Gaston Veil, 44035 Nantes, France. ${ }^{3}$ Service de Médecine Intensive Réanimation, CHU de Grenoble Alpes, 38000 Grenoble, France. ${ }^{4}$ INSERM, U1042, University of Grenoble-Alpes, HP2, 38000 Grenoble, France. ${ }^{5}$ Service de Réanimation Pédiatrique, CHU de Grenoble Alpes, 38000 Grenoble, France. ${ }^{6}$ Service de réanimation, CHU de Monastir, Monastir, Tunisia. ${ }^{7}$ Service de MIR, Hôpital Henri Mondor, APHP, Créteil, France. ${ }^{8}$ Pediatric Emergency Department, CHU Pellegrin Enfants, Bordeaux, France. ${ }^{9}$ Service des Urgences, Hôpital Lariboisière, APHP, Paris, France. ${ }^{10}$ Service des Urgences, CHU de la Réunion, Saint-Denis, France. ${ }^{11}$ Pediatric Intensive Care Unit, Robert Debré Hospital, APHP, Paris, France. ${ }^{12}$ Groupe Hospitalier Pitié-Salpêtrière Charles Foix, Service de Pneumologie, Médecine Intensive et Réanimation (Département R3S), AP-HP, INSERM, UMRS1158 neurophysiologie respiratoire expérimentale et clinique, Sorbonne Université, Paris, France. ${ }^{13}$ Service des Urgences, $\mathrm{CHU}$ de Besançon, Besançon, France. ${ }^{14}$ Médecine Intensive Réanimation, INSERM CIC 1415, réseau CRICS-TriggerSEP, CHRU de Tours and Centre d'Etude des Pathologies Respiratoires, INSERM U1 100, faculté de médecine, Université de Tours, Tours, France. ${ }^{15}$ Pediatric Intensive Care Unit, Women and Children's University Hospital, Nantes, France. ${ }^{16}$ Service des Urgences, CHU de Toulouse, Toulouse, France. ${ }^{17}$ Service de MIR, CHU de Montpelliers, Montpellier, France. ${ }^{18}$ Service des Urgences, CHU de Strasbourg, Strasbourg, France. ${ }^{19}$ Service de MIR, CHRU de Brest, Brest, France. ${ }^{20}$ Pôle Urgences, centre hospitalier du Forez, 42605 Montbrison, France. ${ }^{21}$ Réseau d'urgence Ligérien Ardèche Nord (REULIAN), centre hospitalier Le Corbusier, 42700 Firminy, France. ${ }^{22}$ Département de Pédiatrie Néonatale et Réanimations, CHU de Montpellier, Montpellier, France. ${ }^{23}$ Service de Pneumologie et Réanimation, GH Pitié-Sal pêtrière, 
APHP, Paris, France. ${ }^{24}$ Service des Urgences, centre hospitalier de Cahors, Cahors, France. ${ }^{25}$ Service des Urgences, AP-HP, hôpital la Riboisière, Paris, France. ${ }^{26}$ Pediatric Intensive Care Unit, Women-Mothers and Children's University Hospital, Lyon, France. ${ }^{27}$ service de Pneumologie, CHU de Bordeaux, Pessac, France. ${ }^{28}$ Service des Urgences, CHU de Dijon, faculté de médecine de Dijon, Dijon, France. ${ }^{29}$ INSERM, UMRS_1166-ICAN, Institute of Cardiometabolism and Nutrition, Pitié-Salpêtrière Hospital, Medical Intensive Care Unit, Sorbonne Universités, 75651 Paris Cedex 13, France. ${ }^{30} \mathrm{CHU}$ de Poitiers, Médecine Intensive Réanimation, Poitiers, France. ${ }^{31}$ Service des Urgences, CHU de Bordeaux, Pessac, France. ${ }^{32}$ SAMU 94, CHU Henri Mondor, AP-HP, Créteil, France. ${ }^{33}$ Service des Urgences Adultes, CHU de Grenoble Alpes, 38000 Grenoble, France. ${ }^{34}$ Service de réanimation polyvalente, Hôpital Tenon, APHP, Paris, France. ${ }^{35}$ Pediatric Emergency Department, Women and Children', s University Hospital, Nantes, France. ${ }^{36}$ Service de Réanimation Pédiatrique, APHP Hôpital Trousseau, 75012 Paris, France. ${ }^{37}$ Service de Médecine Intensive Réanimation, APHP Hôpital Saint Louis, 75010 Paris, France. ${ }^{38}$ Service d'Accueil des Urgences, CHU de Nîmes, 30029 Nîmes, France.

Received: 5 July 2019 Accepted: 21 September 2019 Published online: 10 October 2019

\section{References}

1. Global Initiative for Asthma. Global strategy for asthma management and prevention; 2018. https://ginasthma.org/wp-content/uploa ds/2019/01/2018-GINA.pdf.

2. Raherison C, Bourdin A, Bonniaud P, Deslée G, Garcia G, Leroyer C, Taillé C, De Blic J, Dubus J-C, Tillié-Leblond I, Chanez P. Updated guidelines (2015) for management and monitoring of adult and adolescent asthmatic patients (from 12 years and older) of the Société de Pneumologie de Langue Française (SPLF) (Full length text). Rev Mal Respir. 2016;33:279-325

3. Fuhlbrigge A, Peden D, Apter AJ, Boushey HA, Camargo CA, Gern J, Heymann PW, Martinez FD, Mauger D, Teague WG, Blaisdell C. Asthma outcomes: Exacerbations. J Allergy Clin Immunol. 2012;129:S34-48.

4. Chan-Yeung M, Chang JH, Manfreda J, Ferguson A, Becker A. Changes in peak flow, symptom score, and the use of medications during acute exacerbations of asthma. Am J Respir Crit Care Med. 1996;154:889-93.

5. British guideline on the management of asthma SIGN 153; 2016. https://www.sign.ac.uk/assets/grg153.pdf.

6. Ichinose $M$, Sugiura $H$, Nagase $H$, Yamaguchi $M$, Inoue $H$, Sagara $H$, Tamaoki J, Tohda Y, Munakata M, Yamauchi K, Ohta K, Japanese Society of Allergology. Japanese guidelines for adult asthma 2017. Allergol Int. 2017;66:163-89.

7. Salmeron S, Liard R, Elkharrat D, Muir J, Neukirch F, Ellrodt A. Asthma severity and adequacy of management in accident and emergency departments in France: a prospective study. Lancet. 2001;358:629-35.

8. Alvarez GG, Schulzer M, Jung D, Fitzgerald JM. A systematic review of risk factors associated with near-fatal and fatal asthma. Can Respir J. 2005;12:265-70.

9. Spitzer WO, Suissa S, Ernst P, Horwitz RI, Habbick B, Cockcroft D, Boivin JF, McNutt M, Buist AS, Rebuck AS. The use of beta-agonists and the risk of death and near death from asthma. N Engl J Med. 1992;326:501-6.

10. Alvarez GG, Fitzgerald JM. A systematic review of the psychological risk factors associated with near fatal asthma or fatal asthma. Respiration. 2007;74:228-36.

11. Sturdy PM, Victor CR, Anderson HR, Bland JM, Butland BK, Harrison BDW, Peckitt C, Taylor JC, Mortality and Severe Morbidity Working Group of the National Asthma Task Force. Psychological, social and health behaviour risk factors for deaths certified as asthma: a national case-control study. Thorax. 2002;57:1034-9.

12. Gupta D, Keogh B, Chung KF, Ayres JG, Harrison DA, Goldfrad C, Brady AR, Rowan K. Characteristics and outcome for admissions to adult, general critical care units with acute severe asthma: a secondary analysis of the ICNARC Case Mix Programme Database. Crit Care. 2004;8:R112-21.

13. Afessa B, Morales I, Cury JD. Clinical course and outcome of patients admitted to an ICU for status asthmaticus. Chest. 2001;120:1616-21.

14. Hasegawa W, Yamauchi Y, Yasunaga H, Takeshima H, Sakamoto Y, Jo T, Sasabuchi Y, Matsui H, Fushimi K, Nagase T. Prognostic nomogram for inpatients with asthma exacerbation. BMC Pulm Med. 2017;17:108.
15. Weber EJ, Silverman RA, Callaham ML, Pollack CV, Woodruff PG, Clark S, Camargo CA. A prospective multicenter study of factors associated with hospital admission among adults with acute asthma. Am J Med. 2002; 113:371-8.

16. Turner MO, Noertjojo K, Vedal S, Bai T, Crump S, Fitzgerald JM. Risk factors for near-fatal asthma. A case-control study in hospitalized patients with asthma. Am J Respir Crit Care Med. 1998;157:1804-9.

17. McDowell KM, Kercsmar CM, Huang B, Guilbert TW, Kahn RS. Medical and Social Determinants of Health Associated with Intensive Care Admission for Asthma in Children. Ann Am Thorac Soc. 2016;13:1081-8.

18. Mitchell I, Tough SC, Semple LK, Green FH, Hessel PA. Near-fatal asthma: a population-based study of risk factors. Chest. 2002;121:1407-13.

19. Belessis Y, Dixon S, Thomsen A, Duffy B, Rawlinson W, Henry R, Morton J. Risk factors for an intensive care unit admission in children with asthma. Pediatr Pulmonol. 2004;37:201-9.

20. Tsai TW, Gallagher EJ, Lombardi G, Gennis P, Carter W. Guidelines for the selective ordering of admission chest radiography in adult obstructive airway disease. Ann Emerg Med. 1993;22:1854-8.

21. Carruthers DM, Harrison BD. Arterial blood gas analysis or oxygen saturation in the assessment of acute asthma? Thorax. 1995;50:186-8.

22. Kelly A-M, Kerr D, Middleton P. Validation of venous pCO2 to screen for arterial hypercarbia in patients with chronic obstructive airways disease. J Emerg Med. 2005;28:377-9.

23. Dankoff S, Li P, Shapiro AJ, Varshney T, Dubrovsky AS. Point of care lung ultrasound of children with acute asthma exacerbations in the pediatric ED. Am J Emerg Med. 2017;35:615-22.

24. Shrestha M, Bidadi K, Gourlay S, Hayes J. Continuous vs intermittent albuterol, at high and low doses, in the treatment of severe acute asthma in adults. Chest. 1996;110:42-7.

25. Rudnitsky GS, Eberlein RS, Schoffstall JM, Mazur JE, Spivey WH. Comparison of intermittent and continuously nebulized albuterol for treatment of asthma in an urban emergency department. Ann Emerg Med. 1993;22:1842-6.

26. Camargo $\mathrm{CA}$, Spooner $\mathrm{CH}$, Rowe BH. Continuous versus intermittent beta-agonists in the treatment of acute asthma. Cochrane Database Syst Rev. 2003. https://doi.org/10.1002/14651858.CD001115.

27. Travers A, Jones AP, Kelly K, Barker SJ, Camargo CA, Rowe BH. Intravenous beta2-agonists for acute asthma in the emergency department. Cochrane Database Syst Rev. 2001. https://doi.org/10.1002/14651858. CD002988.

28. Khine H, Fuchs SM, Saville AL. Continuous vs intermittent nebulized albuterol for emergency management of asthma. Acad Emerg Med. 1996;3:1019-24.

29. Kenyon CC, Fieldston ES, Luan X, Keren R, Zorc JJ. Safety and effectiveness of continuous aerosolized albuterol in the non-intensive care setting. Pediatrics. 2014;134:e976-82.

30. Lanes SF, Garrett JE, Wentworth CE, Fitzgerald JM, Karpel JP. The effect of adding ipratropium bromide to salbutamol in the treatment of acute asthma: a pooled analysis of three trials. Chest. 1998;114:365-72.

31. Rodrigo G, Rodrigo C, Burschtin O. A meta-analysis of the effects of ipratropium bromide in adults with acute asthma. Am J Med. 1999;107:363-70.

32. Stoodley RG, Aaron SD, Dales RE. The role of ipratropium bromide in the emergency management of acute asthma exacerbation: a metaanalysis of randomized clinical trials. Ann Emerg Med. 1999;34:8-18.

33. Kirkland SW, Vandenberghe C, Voaklander B, Nikel T, Campbell S, Rowe $\mathrm{BH}$. Combined inhaled beta-agonist and anticholinergic agents for emergency management in adults with asthma. Cochrane Database Syst Rev. 2017;1:CD001284.

34. Griffiths B, Ducharme FM. Combined inhaled anticholinergics and short-acting beta2-agonists for initial treatment of acute asthma in children. Cochrane Database Syst Rev. 2013. https://doi.org/10.1002/14651 858.CD000060.pub2.

35. Britton J, Hanley SP, Garrett HV, Hadfield JW, Tattersfield AE. Dose related effects of salbutamol and ipratropium bromide on airway calibre and reactivity in subjects with asthma. Thorax. 1988;43:300-5.

36. Rowe BH, Spooner CH, Ducharme FM, Bretzlaff JA, Bota GW. Corticosteroids for preventing relapse following acute exacerbations of asthma. Cochrane Database Syst Rev. 2001. https://doi.org/10.1002/14651858. CD000195.pub2. 
37. Edmonds ML, Milan SJ, Brenner BE, Camargo CA, Rowe BH. Inhaled steroids for acute asthma following emergency department discharge. Cochrane Database Syst Rev. 2012;12:CD002316.

38. Manser R, Reid D, Abramson M. Corticosteroids for acute severe asthma in hospitalised patients. Cochrane Database Syst Rev. 2001. https://doi. org/10.1002/14651858.CD001740.

39. Schuh S, Reisman J, Alshehri M, Dupuis A, Corey M, Arseneault R, Alothman G, Tennis O, Canny G. A comparison of inhaled fluticasone and oral prednisone for children with severe acute asthma. N Engl J Med. 2000;343:689-94.

40. Devidayal, Singhi S, Kumar L, Jayshree M. Efficacy of nebulized budesonide compared to oral prednisolone in acute bronchial asthma. Acta Paediatr. 1999;88:835-40.

41. Ancheta VA, Jiao AGQ, Erguiza GSD, Arellano MA, Dizon CC, Catacutan MS. comparison of inhaled fluticasone propionate versus intravenous hydrocortisone in the treatment of severe asthma exacerbation in children aged 6-18 years. Chest. 2008;134:24S.

42. Matthews EE, Curtis PD, McLain BI, Morris LS, Turbitt ML. Nebulized budesonide versus oral steroid in severe exacerbations of childhood asthma. Acta Paediatr. 1999;88:841-3.

43. Beckhaus AA, Riutort MC, Castro-Rodriguez JA. Inhaled versus systemic corticosteroids for acute asthma in children. A systematic review. Pediatr Pulmonol. 2014;49:326-34.

44. Goodacre S, Cohen J, Bradburn M, Stevens J, Gray A, Benger J, Coats $\mathrm{T}$, $3 \mathrm{Mg}$ Research Team. The $3 \mathrm{Mg}$ trial: a randomised controlled trial of intravenous or nebulised magnesium sulphate versus placebo in adults with acute severe asthma. Health Technol Assess. 2014;18:1-168.

45. Skobeloff EM, Spivey WH, McNamara RM, Greenspon L. Intravenous magnesium sulfate for the treatment of acute asthma in the emergency department. JAMA. 1989;262:1210-3.

46. Mangat HS, D'Souza GA, Jacob MS. Nebulized magnesium sulphate versus nebulized salbutamol in acute bronchial asthma: a clinical trial. Eur Respir J. 1998;12:341-4.

47. Bloch H, Silverman R, Mancherje N, Grant S, Jagminas L, Scharf SM. Intravenous magnesium sulfate as an adjunct in the treatment of acute asthma. Chest. 1995;107:1576-81.

48. Egelund TA, Wassil SK, Edwards EM, Linden S, Irazuzta JE. Highdose magnesium sulfate infusion protocol for status asthmaticus: a safety and pharmacokinetics cohort study. Intensive Care Med. 2013;39:117-22.

49. Kew KM, Kirtchuk L, Michell Cl. Intravenous magnesium sulfate for treating adults with acute asthma in the emergency department. Cochrane Database Syst Rev. 2014. https://doi.org/10.1002/14651 858.CD010909.pub2.

50. Mohammed S, Goodacre S. Intravenous and nebulised magnesium sulphate for acute asthma: systematic review and meta-analysis. Emerg Med J. 2007;24:823-30.

51. Torres S, Sticco N, Bosch JJ, Iolster T, Siaba A, Rocca Rivarola M, Schnitzler E. Effectiveness of magnesium sulfate as initial treatment of acute severe asthma in children, conducted in a tertiary-level university hospital: a randomized, controlled trial. Arch Argent Pediatr. 2012;110:291-6.

52. Shan Z, Rong Y, Yang W, Wang D, Yao P, Xie J, Liu L. Intravenous and nebulized magnesium sulfate for treating acute asthma in adults and children: a systematic review and meta-analysis. Respir Med. 2013;107:321-30.

53. Marchello C, Dale AP, Thai TN, Han DS, Ebell MH. Prevalence of atypical pathogens in patients with cough and community-acquired pneumonia: a meta-analysis. Ann Fam Med. 2016;14:552-66.

54. Talbot TR, Hartert TV, Mitchel E, Halasa NB, Arbogast PG, Poehling KA, Schaffner W, Craig AS, Griffin MR. Asthma as a risk factor for invasive pneumococcal disease. N Engl J Med. 2005;352:2082-90.

55. Gielen V, Johnston SL, Edwards MR. Azithromycin induces anti-viral responses in bronchial epithelial cells. Eur Respir J. 2010;36:646-54.

56. Kobayashi Y, Wada H, Rossios C, Takagi D, Higaki M, Mikura S, Goto $\mathrm{H}$, Barnes PJ, Ito K. A novel macrolide solithromycin exerts superior anti-inflammatory effect via NF-KB inhibition. J Pharmacol Exp Ther. 2013;345:76-84.

57. Johnston SL, Blasi F, Black PN, Martin RJ, Farrell DJ, Nieman RB, Investigators TELICAST. The effect of telithromycin in acute exacerbations of asthma. N Engl J Med. 2006;354:1589-600.
58. Johnston SL, Szigeti M, Cross M, Brightling C, Chaudhuri R, Harrison T, Mansur A, Robison L, Sattar Z, Jackson D, Mallia P, Wong E, Corrigan C, Higgins B, Ind P, Singh D, Thomson NC, Ashby D, Chauhan A, Trial Team AZALEA. Azithromycin for acute exacerbations of asthma: the AZALEA randomized clinical trial. JAMA Intern Med. 2016;176:1630-7.

59. Graham VA, Milton AF, Knowles GK, Davies RJ. Routine antibiotics in hospital management of acute asthma. Lancet. 1982;1:418-20.

60. Graham V, Lasserson T, Rowe BH. Antibiotics for acute asthma. Cochrane Database Syst Rev. 2001. https://doi.org/10.1002/14651 858.CD002741.

61. Rowe BH, Villa-Roel C, Abu-Laban RB, Stenstrom R, Mackey D, Stiell IG, Campbell S, Young B. Admissions to Canadian hospitals for acute asthma: a prospective, multicentre study. Can Respir J. 2010;17:25-30.

62. Perrin K, Wijesinghe M, Healy B, Wadsworth K, Bowditch R, Bibby S, Baker T, Weatherall M, Beasley R. Randomised controlled trial of high concentration versus titrated oxygen therapy in severe exacerbations of asthma. Thorax. 2011;66:937-41.

63. Rodrigo GJ, Rodriquez Verde M, Peregalli V, Rodrigo C. Effects of short-term $28 \%$ and $100 \%$ oxygen on $\mathrm{PaCO} 2$ and peak expiratory flow rate in acute asthma: a randomized trial. Chest. 2003; 124:1312-7

64. Chien JW, Ciufo R, Novak R, Skowronski M, Nelson J, Coreno A, McFadden ER. Uncontrolled oxygen administration and respiratory failure in acute asthma. Chest. 2000;117:728-33.

65. Ganesh A, Shenoy S, Doshi V, Rishi M, Molnar J. Use of noninvasive ventilation in adult patients with acute asthma exacerbation. Am J Ther. 2015:22:431-4.

66. Fernández MM, Villagrá A, Blanch L, Fernández R. Non-invasive mechanical ventilation in status asthmaticus. Intensive Care Med. 2001;27:486-92.

67. Murase K, Tomii K, Chin K, Tsuboi T, Sakurai A, Tachikawa R, Harada Y, Takeshima Y, Hayashi M, Ishihara K. The use of non-invasive ventilation for life-threatening asthma attacks: changes in the need for intubation. Respirology. 2010;15:714-20.

68. Stefan MS, Nathanson BH, Lagu T, Priya A, Pekow PS, Steingrub JS, Hill NS, Goldberg RJ, Kent DM, Lindenauer PK. Outcomes of noninvasive and invasive ventilation in patients hospitalized with asthma exacerbation. Ann Am Thorac Soc. 2016;13:1096-104.

69. Soroksky A, Stav D, Shpirer I. A pilot prospective, randomized, placebocontrolled trial of bilevel positive airway pressure in acute asthmatic attack. Chest. 2003;123:1018-25.

70. Soma T, Hino M, Kida K, Kudoh S. A prospective and randomized study for improvement of acute asthma by non-invasive positive pressure ventilation (NPPV). Intern Med. 2008;47:493-501.

71. Gupta D, Nath A, Agarwal R, Behera D. A prospective randomized controlled trial on the efficacy of noninvasive ventilation in severe acute asthma. Respir Care. 2010;55:536-43.

72. Brandao DC, Lima VM, Filho VG, Silva TS, Campos TF, Dean E, de Andrade $A D$. Reversal of bronchial obstruction with bi-level positive airway pressure and nebulization in patients with acute asthma. J Asthma. 2009;46:356-61.

73. Lim WJ, Mohammed Akram R, Carson KV, Mysore S, Labiszewski NA, Wedzicha JA, Rowe BH, Smith BJ. Non-invasive positive pressure ventilation for treatment of respiratory failure due to severe acute exacerbations of asthma. Cochrane Database Syst Rev. 2012;12:CD004360.

74. Rochwerg B, Brochard L, Elliott MW, Hess D, Hill NS, Nava S, Navalesi P, Antonelli M, Brozek J, Conti G, Ferrer M, Guntupalli K, Jaber S, Keenan S, Mancebo J, Mehta S, Raoof S. Official ERS/ATS clinical practice guidelines: noninvasive ventilation for acute respiratory failure. Eur Respir J. 2017. https://doi.org/10.1183/13993003.02426-2016.

75. Thill PJ, McGuire JK, Baden HP, Green TP, Checchia PA. Noninvasive positive-pressure ventilation in children with lower airway obstruction. Pediatr Crit Care Med. 2004;5:337-42.

76. Basnet S, Mander G, Andoh J, Klaska H, Verhulst S, Koirala J. Safety, efficacy, and tolerability of early initiation of noninvasive positive pressure ventilation in pediatric patients admitted with status asthmaticus: a pilot study. Pediatr Crit Care Med. 2012;13:393-8.

77. Mayordomo-Colunga J, Medina A, Rey C, Concha A, Menéndez S, Arcos ML, Vivanco-Allende A. Non-invasive ventilation in pediatric status asthmaticus: a prospective observational study. Pediatr Pulmonol. 2011;46:949-55. 
78. Baudin F, Buisson A, Vanel B, Massenavette B, Pouyau R, Javouhey E. Nasal high flow in management of children with status asthmaticus: a retrospective observational study. Ann Intensive Care. 2017;7:55.

79. Pilar J, Modesto I Alapont V, Lopez-Fernandez YM, Lopez-Macias O, Garcia-Urabayen D, Amores-Hernandez I. High-flow nasal cannula therapy versus non-invasive ventilation in children with severe acute asthma exacerbation: an observational cohort study. Med Intensiva. 2017:41:418-24.

80. Pendergraft TB, Stanford RH, Beasley R, Stempel DA, Roberts C, McLaughlin T. Rates and characteristics of intensive care unit admissions and intubations among asthma-related hospitalizations. Ann Allergy Asthma Immunol. 2004;93:29-35.

81. Brenner B, Corbridge T, Kazzi A. Intubation and mechanical ventilation of the asthmatic patient in respiratory failure. J Emerg Med. 2009;37:S23-34

82. Quintard H, I'Her E, Pottecher J, Adnet F, Constantin J-M, De Jong A, Diemunsch P, Fesseau R, Freynet A, Girault C, Guitton C, Hamonic Y, Maury E, Mekontso-Dessap A, Michel F, Nolent P, Perbet S, Prat G, Roquilly A, Tazarourte K, Terzi N, Thille AW, Alves M, Gayat E, Donetti L. Intubation and extubation of the ICU patient. Anaesth Crit Care Pain Med. 2017;36:327-41.

83. Ono Y, Kikuchi H, Hashimoto K, Sasaki T, Ishii J, Tase C, Shinohara K. Emergency endotracheal intubation-related adverse events in bronchial asthma exacerbation: can anesthesiologists attenuate the risk? J Anesth. 2015;29:678-85.

84. Newth CJL, Meert KL, Clark AE, Moler FW, Zuppa AF, Berg RA, Pollack MM, Sward KA, Berger JT, Wessel DL, Harrison RE, Reardon J, Carcillo JA, Shanley TP, Holubkov R, Dean JM, Doctor A, Nicholson CE, Eunice Kennedy Shriver National Institute of Child Health and Human Development Collaborative Pediatric Critical Care Research Network. Fatal and near-fatal asthma in children: the critical care perspective. J Pediatr. 2012;161:214-221.e3.

85. Tuxen DV, Lane $\mathrm{S}$. The effects of ventilatory pattern on hyperinflation, airway pressures, and circulation in mechanical ventilation of patients with severe air-flow obstruction. Am Rev Respir Dis. 1987:136:872-9.

86. Williams TJ, Tuxen DV, Scheinkestel CD, Czarny D, Bowes G. Risk factors for morbidity in mechanically ventilated patients with acute severe asthma. Am Rev Respir Dis. 1992;146:607-15.

87. Tuxen DV, Williams TJ, Scheinkestel CD, Czarny D, Bowes G. Use of a measurement of pulmonary hyperinflation to control the level of mechanical ventilation in patients with acute severe asthma. Am Rev Respir Dis. 1992;146:1136-42.

88. Leatherman JW, MCArthur C, Shapiro RS. Effect of prolongation of expiratory time on dynamic hyperinflation in mechanically ventilated patients with severe asthma. Crit Care Med. 2004;32:1542-5.

89. Oddo M, Feihl F, Schaller M-D, Perret C. Management of mechanical ventilation in acute severe asthma: practical aspects. Intensive Care Med. 2006;32:501-10.

90. Leatherman JW, Ravenscraft SA. Low measured auto-positive endexpiratory pressure during mechanical ventilation of patients with severe asthma: hidden auto-positive end-expiratory pressure. Crit Care Med. 1996;24:541-6.

91. Kesler SM, Sprenkle MD, David WS, Leatherman JW. Severe weakness complicating status asthmaticus despite minimal duration of neuromuscular paralysis. Intensive Care Med. 2009;35:157-60.

92. Adnet F, Dhissi G, Borron SW, Galinski M, Rayeh F, Cupa M, Pourriat JL, Lapostolle F. Complication profiles of adult asthmatics requiring paralysis during mechanical ventilation. Intensive Care Med. 2001;27:1729-36.

93. Hemming A, MacKenzie I, Finfer S. Response to ketamine in status asthmaticus resistant to maximal medical treatment. Thorax. 1994:49:90-1.

94. Golding CL, Miller JL, Gessouroun MR, Johnson PN. Ketamine continuous infusions in critically ill infants and children. Ann Pharmacother. 2016;50:234-41.

95. Achar MN, Achar KN. Efficacy of ketamine infusion in refractory asthma complicated by acute myocardial infarction. Anaesth Intensive Care. 1993;21:115-7.

96. Mondoñedo JR, McNeil JS, Amin SD, Herrmann J, Simon BA, Kaczka DW. Volatile anesthetics and the treatment of severe bronchospasm: a concept of targeted delivery. Drug Discov Today Dis Models. 2015;15:43-50.

97. Jat KR, Chawla D. Ketamine for management of acute exacerbations of asthma in children. Cochrane Database Syst Rev. 2012;11:293.

98. Char DS, Ibsen LM, Ramamoorthy C, Bratton SL. Volatile anesthetic rescue therapy in children with acute asthma: innovative but costly or just costly? Pediatr Crit Care Med. 2013;14:343-50.

99. Turner DA, Heitz D, Cooper MK, Smith PB, Arnold JH, Bateman ST. Isoflurane for life-threatening bronchospasm: a 15-year single-center experience. Respir Care. 2012;57:1857-64.

100. Carter ER, Webb CR, Moffitt DR. Evaluation of heliox in children hospitalized with acute severe asthma. A randomized crossover trial. Chest. 1996;109:1256-61.

101. Kudukis TM, Manthous CA, Schmidt GA, Hall JB, Wylam ME. Inhaled helium-oxygen revisited: effect of inhaled helium-oxygen during the treatment of status asthmaticus in children. J Pediatr. 1997;130:217-24.

102. Henderson SO, Acharya P, Kilaghbian T, Perez J, Korn CS, Chan LS. Use of heliox-driven nebulizer therapy in the treatment of acute asthma. Ann Emerg Med. 1999:33:141-6.

103. Kass JE, Terregino CA. The effect of heliox in acute severe asthma: a randomized controlled trial. Chest. 1999;1 16:296-300.

104. L'Her E, Monchi M, Joly B, Marichy J, Lejay M, Dhainaut JF. Helium-oxygen breathing in the early emergency care of acute severe asthma: a randomized pilot study. Eur J Emerg Med. 2000;7:271-5.

105. Dorfman TA, Shipley ER, Burton JH, Jones P, Mette SA. Inhaled heliox does not benefit ED patients with moderate to severe asthma. Am J Emerg Med. 2000;18:495-7.

106. Rose JS, Panacek EA, Miller P. Prospective randomized trial of helioxdriven continuous nebulizers in the treatment of asthma in the emergency department. J Emerg Med. 2002;22:133-7.

107. Kress JP, Noth I, Gehlbach BK, Barman N, PohIman AS, Miller A, Morgan S, Hall JB. The utility of albuterol nebulized with heliox during acute asthma exacerbations. Am J Respir Crit Care Med. 2002;165:1317-21.

108. Kim IK, Phrampus E, Venkataraman S, Pitetti R, Saville A, Corcoran T, Gracely E, Funt N, Thompson A. Helium/oxygen-driven albuterol nebulization in the treatment of children with moderate to severe asthma exacerbations: a randomized, controlled trial. Pediatrics. 2005;116:1127-33.

109. Lee DL, Hsu C-W, Lee H, Chang H-W, Huang Y-CT. Beneficial effects of albuterol therapy driven by heliox versus by oxygen in severe asthma exacerbation. Acad Emerg Med. 2005;12:820-7.

110. Xie L, Liu Y, Chen L, Hao F, Jin G, Zhao H. Inhaling beta(2)-agonist with heliox-driven in bronchial asthma. Chin Med J. 2003;116:1011-5.

111. Rodrigo GJ, Castro-Rodriguez JA. Heliox-driven $\beta 2$-agonists nebulization for children and adults with acute asthma: a systematic review with meta-analysis. Ann Allergy Asthma Immunol. 2014;112:29-34.

112. Cates CJ, Welsh EJ, Rowe BH. Holding chambers (spacers) versus nebulisers for beta-agonist treatment of acute asthma. Cochrane Database Syst Rev. 2013. https://doi.org/10.1002/14651858.CD000 052.pub3.

113. Laube BL, Janssens HM, de Jongh FHC, Devadason SG, Dhand R, Diot P, Everard ML, Horvath I, Navalesi P, Voshaar T, Chrystyn H, European Respiratory Society, International Society for Aerosols in Medicine. What the pulmonary specialist should know about the new inhalation therapies. Eur Respir J. 2011:37:1308-31.

114. Caille V, Ehrmann S, Boissinot E, Perrotin D, Diot P, Dequin P-F. Influence of jet nebulization and oxygen delivery on the fraction of inspired oxygen: an experimental model. J Aerosol Med Pulm Drug Deliv. 2009;22:255-61.

115. Dolovich MB, Dhand R. Aerosol drug delivery: developments in device design and clinical use. Lancet. 2011;377:1032-45.

116. Réminiac F, Vecellio L, Heuzé-Vourc'h N, Petitcollin A, Respaud R, Cabrera M, Pennec DL, Diot P, Ehrmann S. Aerosol therapy in adults receiving high flow nasal cannula oxygen therapy. J Aerosol Med Pulm Drug Deliv. 2016;29:134-41.

117. Ari A, Fink JB, Dhand R. Inhalation therapy in patients receiving mechanical ventilation: an update. J Aerosol Med Pulm Drug Deliv. 2012;25:319-32. 
118. Brenner K, Abrams DC, Agerstrand CL, Brodie D. Extracorporeal carbon dioxide removal for refractory status asthmaticus: experience in distinct exacerbation phenotypes. Perfusion. 2014;29:26-8.

119. Di Lascio G, Prifti E, Messai E, Peris A, Harmelin G, Xhaxho R, Fico A, Sani G, Bonacchi M. Extracorporeal membrane oxygenation support for life-threatening acute severe status asthmaticus. Perfusion. 2017;32:157-63.

120. Hebbar KB, Petrillo-Albarano T, Coto-Puckett W, Heard M, Rycus PT, Fortenberry JD. Experience with use of extracorporeal life support for severe refractory status asthmaticus in children. Crit Care. 2009;13:R29.

121. Mikkelsen ME, Woo YJ, Sager JS, Fuchs BD, Christie JD. Outcomes using extracorporeal life support for adult respiratory failure due to status asthmaticus. ASAIO J. 2009;55:47-52.

122. Gatheral TL, Rushton A, Evans DJ, Mulvaney CA, Halcovitch NR, Whiteley G, Eccles FJ, Spencer S. Personalised asthma action plans for adults with asthma. Cochrane Database Syst Rev. 2017;4:CD011859.

123. Tapp S, Lasserson TJ, Rowe BH. Education interventions for adults who attend the emergency room for acute asthma. Cochrane Database Syst Rev. 2007. https://doi.org/10.1002/14651858.CD003000. pub2.

124. Normansell R, Kew KM, Mansour G. Different oral corticosteroid regimens for acute asthma. Cochrane Database Syst Rev. 2016. https ://doi.org/10.1002/14651858.CD011801.pub2.

125. Moghaddas F, Smith C, Pilcher D, O'Hehir R, Hew M, Dabscheck E. Need for intensive care in patients admitted for asthma: red flags from the social history. Respirology. 2016;21:1251-4.

126. Sears MR, Greene JM, Willan AR, Wiecek EM, Taylor DR, Flannery EM, Cowan JO, Herbison GP, Silva PA, Poulton R. A longitudinal, population-based, cohort study of childhood asthma followed to adulthood. N Engl J Med. 2003;349:1414-22.
127. Louie S, Morrissey BM, Kenyon NJ, Albertson TE, Avdalovic M. The critically ill asthmatic - from ICU to discharge. Clin Rev Allergy Immunol. 2012:43:30-44

128. Cundiff KM, Gerard JM, Flood RG. Critical care interventions for asthmatic patients admitted from the emergency department to the pediatric intensive care unit. Pediatr Emerg Care. 2018;34:385-9.

129. Maue DK, Krupp N, Rowan CM. Pediatric asthma severity score is associated with critical care interventions. World J Clin Pediatr. 2017:6:34-9.

130. Hasegawa K, Cydulka RK, Sullivan AF, Langdorf MI, Nonas SA, Nowak RM, Wang NE, Camargo CA. Improved management of acute asthma among pregnant women presenting to the ED. Chest. 2015; 147:406-14

131. Murphy VE, Clifton VL, Gibson PG. Asthma exacerbations during pregnancy: incidence and association with adverse pregnancy outcomes. Thorax. 2006;61:169-76.

132. Rejnö G, Lundholm C, Gong T, Larsson K, Saltvedt S, Almqvist C. Asthma during pregnancy in a population-based study-pregnancy complications and adverse perinatal outcomes. PLoS ONE. 2014;9:e104755.

133. Namazy JA, Murphy VE, Powell H, Gibson PG, Chambers C, Schatz M. Effects of asthma severity, exacerbations and oral corticosteroids on perinatal outcomes. Eur Respir J. 2013;41:1082-90.

\section{Publisher's Note}

Springer Nature remains neutral with regard to jurisdictional claims in published maps and institutional affiliations.

\section{Submit your manuscript to a SpringerOpen ${ }^{\circ}$ journal and benefit from:}

- Convenient online submission

- Rigorous peer review

- Open access: articles freely available online

- High visibility within the field

Retaining the copyright to your article

Submit your next manuscript at $\boldsymbol{\nabla}$ springeropen.com 